\title{
As paixões no discurso jornalístico: um estudo dos conceitos de David Hume em confluência com os estudos retóricos
}

\section{Amanda Muniz}

\section{Considerações iniciais}

$\mathrm{D}$ avid Hume foi filósofo, historiador, sociólogo e economista escocês do período do Iluminismo (século XVIII). É considerado um dos mais importantes filósofos iluministas ocidentais e um dos pais do empirismo. De acordo com Mascarenhas (2005), entre 1724 e 1726, [Hume] estudou Direito na Universidade de Edimburgo. Como não gostava do curso, aprofundou seus estudos em Filosofia, Economia e Literatura.

De acordo com o filósofo David Hume (1958a, 1958b, 2009, 2011), na classificação das paixões estas se dividem em diretas (pesar ou sofrimento, medo, desejo, alegria, aversão), que são as primeiras reações, e indiretas (amor, ódio, orgulho, humildade), consequência daquelas. Alinhando-se os conceitos de Hume à contribuição dos estudos retóricos, pratica-se uma reflexão sobre a noção das paixões, motivada pela observação de textos jornalísticos da mídia escrita, na qual reconhecemos o uso de discursos epidíticos.

Diante da constatação da existência das paixões no discurso epidítico jornalístico, questiona-se de que maneira essas paixões podem mover o auditório, como se apresentam nesse tipo de discurso e qual a relevância de cada elemento passional utilizado na sua constituição. Inicia-se pela hipótese de que os elementos passionais são estratégias para mover o auditório.

Essa hipótese fundamentou-se na leitura de estudos da área da retórica em confluência com pesquisas sobre conceitos de David Hume, que, ao tentar definir o conceito de paixão, confessa ser uma tarefa difícil precisá-lo. O filósofo, 
entretanto, propôs toda uma doutrina, classificação e considerações sobre as relações das paixões entre si, como também suas transformações. As paixões furtam-se a uma definição precisa, embora o estudioso acredite que as operações que as caracterizam sejam passíveis de uma descrição científica.

Apesar da dificuldade de definição do conceito, as paixões podem ser definidas como impressões simples, ou seja, não podem ser constituídas por elementos mais simples que elas ou não podem ser reduzidas a partes. Essa simplicidade das paixões não impediu que Hume as enumerasse e as comparasse em sua teoria sobre as paixões, apresentada no Livro II do Tratado da Natureza Humana e na obra intitulada Dissertação sobre as Paixões, suas obras sobre as paixões, que servirão de base para este estudo. O que Hume busca nessas duas obras é estabelecer certas condições em que as paixões aparecem. Tendo como critério de diferenciação das paixões o critério causal, o autor distinguirá os afetos em diretos e indiretos.

Entre os dois tipos de afetos, o estudo das paixões indiretas é que terá importância capital, pois estas vão conduzir Hume à análise das ações humanas e às relações em sociedade. Por não procederem unicamente dos sentimentos de prazer e dor, como as paixões diretas, mas também de uma relação entre impressões e as ideias do outro ou do próprio eu, as paixões indiretas tornam-se imprescindíveis para o estudo e a análise de questões relativas ao surgimento e desenvolvimento da sociedade e das relações estabelecidas no interior desta.

Tais proposições incitaram a pretender o objetivo geral deste capítulo, o diálogo entre as concepções do filósofo e os estudos retóricos, apoiados em Reboul (2000), que ressalta não se ensinar mais retórica como arte de produzir discursos, senão como arte de interpretá-los. O autor ainda ensina o poder de persuasão do discurso epidítico: "O epidítico é persuasivo, mas a longo prazo, ao versar sobre problemas que não exigem decisões imediatas. Usando o exemplo para fazer o elogio de certo herói, reforça o sentimento cívico e patriótico". ${ }^{1} \mathrm{Da}$ junção dos conceitos humeanos e dos estudos retóricos, será analisado como as paixões movem os leitores nos discursos epidíticos no meio jornalístico.

Diante dos objetivos, depara-se com a necessidade de optar por um método para seleção do material de análise. Quanto às formas de seleção dos tipos de paixões - diretas e indiretas -, tal como apresenta Hume, como mostra a retórica, será possível apresentar os elementos passionais dentro do tipo de discurso epidítico.

$\overline{1 \text { Reboul, 2000, p. 46-47 }}$ 
As paixões no discurso jornalístico: um estudo dos conceitos

\section{As paixões em Hume}

Entre os principais aspectos que caracterizam o conceito de paixão na teoria humeana está o caráter de determinação à ação. Só os afetos levam o sujeito a agir de maneira efetiva, apenas eles o impulsionam à ação.

Todas as paixões diretas possuem como característica essencial a origem das sensações agradáveis ou desagradáveis, do prazer ou da dor, do bem ou do mal. Adiante, o conceito de Hume sobre as paixões e razão:

No que diz respeito a todas essas paixões, as causas são aquilo que desperta a emoção; o objeto é aquilo para o qual a mente dirige sua visão quando a emoção é despertada. Nosso mérito, por exemplo, suscita orgulho, e é essencial para o orgulho voltar nossa visão sobre nós mesmos com complacência e satisfação.

Ora, como as causas dessas paixões são muito numerosas e diversas, embora seu objeto seja uniforme e simples, pode ser um assunto curioso considerar qual é a circunstância em que todas essas diversas causas coincidem, ou, em outras palavras, qual é a verdadeira causa eficiente da paixão. Começaremos pelo orgulho e a humildade. ${ }^{2}$

Verifica-se que, nesse estudo o filósofo enfoca as paixões para falar daquilo que comumente entendemos por paixão: emoção violenta e sensível da mente que ocorre quando se apresenta um bem ou um mal, ou qualquer objeto que, pela formação original de nossas faculdades, seja propício a despertar um apetite.

Com a palavra razão, referimo-nos a afetos exatamente da mesma espécie que os anteriores, mas que operam mais calmamente, sem causar desordem no temperamento; essa tranquilidade faz que nos enganemos a seu respeito, vendo-os exclusivamente como conclusões de nossas faculdades intelectuais. ${ }^{3}$

O autor explica: as paixões diretas e indiretas são naturais do homem, e também são contrárias, são calmas e são temperamentais. Assim completa o filósofo: "A razão, por si só, é inteiramente impotente quanto a esse aspecto. As regras da moral não são conclusões de nossa razão." ${ }^{4} \mathrm{O}$ filósofo defende que as regras da moral são consequências das paixões. 
Segundo o filósofo, para existir a moral, é necessário ter a razão. Mas, para o ser humano adquirir a razão a fim de agir com moral, precisa, antes de tudo, das paixões.

\section{RAZÃO $\rightarrow$ MORAL \\ PAIXÕES $\rightarrow$ RAZÃO $\rightarrow$ MORAL}

O filósofo explica que a razão não só era tida como contrária às paixões como superior e soberana, enquanto as paixões eram tidas como cegas e enganosas. ${ }^{5}$ Tendo em vista essa dicotomia, acreditava-se que até as ações virtuosas eram aquelas motivadas e reguladas pela razão, isto é, aquelas que não tinham influência das paixões. Hume, porém, buscou mostrar que essa crença é equivocada em dois pontos.

\section{A felicidade por meio de elementos passionais}

Luxo e refinamento, em Hume (1958b), são fenômenos possíveis apenas em uma sociedade que reflita estabilidade nos comportamentos e ações humanas presentes nas trocas da sociedade, fruto do compartilhamento e da reciprocidade dos afetos. Da mesma maneira, na sociedade em que um tipo de luxo inocente, conforme determinado pelo filósofo, possa ser cultivado, essa sociedade terá de possuir instituições reguladoras fortes e capazes de manter o equilíbrio do corpo social e a harmonia dos afetos. Para explicar o luxo e a paixão pelos objetos que os tornam refinados, Hume, em Tratado da Natureza Humana, fala de orgulho e humildade, entendendo estes como causas naturais do homem, que possivelmente conquistaria a felicidade por meio dessas paixões:

Mas, embora o orgulho e a humildade tenham como suas causas naturais e mais imediatas as qualidades de nossa mente e de nosso corpo, isto é, do "eu", descobrimos por experiência que muitos outros objetos produzem esses afetos. Encontramos vaidade a respeito de casas, jardins, carruagens e outros objetos externos, assim como a respeito do mérito e talentos pessoais. Isso ocorre quando os objetos externos adquirem alguma relação particular conosco, e estão associados ou ligados a nós... ${ }^{6}$ 
As paixões no discurso jornalístico: um estudo dos conceitos

Portanto, seguindo essa última linha de raciocínio, as paixões determinariam todas as ações humanas, mas não estariam fundadas unicamente nos prospectos das sensações de dor e prazer. As paixões, enquanto determinadoras da vontade e da vaidade, não estariam circunscritas somente às determinações do prazer, ou seja, o indivíduo não agiria unicamente levando em consideração a perspectiva de um prazer (bem) futuro. Hume (1958) percebe a felicidade nos prazeres, no orgulho, nos sentidos na boa qualidade dos vinhos, das frutas, ou dos alimentos, produzidos por ela; da suavidade ou vigor de sua linguagem, entre outras particularidades dessa espécie. Esses objetos têm claramente uma referência aos prazeres dos sentidos, e são considerados originalmente como agradáveis ao tato, ao paladar, ou ao ouvido. O filósofo ainda questiona que não se poderiam tornar-se causa de orgulho a não ser por meio dessas transições citadas.

Em suma, verifica-se que a teoria humeana do prazer é formada pela junção da paixão, como o orgulho, e do fenômeno luxo e refinamento, que, segundo o filósofo, infere a felicidade humana. Tudo que é agradável e bom faz bem, dá-nos orgulho e se torna luxuoso, portanto, nos traz a felicidade. Enfim, para o filósofo, felicidade é sentir orgulho das riquezas que temos, desejamos, a fim de satisfazer nossa vaidade, que todas aquelas pessoas que tem alguma relação conosco igualmente as possuam, e nos envergonhamos delas quando, entre nossos amigos e parentes, elas são humildes ou pobres. Assim, como considera-se que os antepassados são os parentes mais próximos, presume-se naturalmente ser de uma boa família e descendentes de uma longa sucessão de antepassados ricos e honrados. ${ }^{7}$

De acordo com Hume (2009), as paixões são motivos determinantes de nossas ações, inclusive ser feliz e ter prazer. Constata-se que a capacidade dos artifícios de dirigir a conduta dos indivíduos, por meio de regrais gerais, não é da natureza de uma ideia reguladora externa aos artifícios, mas se deriva da criatividade de invenção das paixões.

\section{O discurso epidítico em confluência com as paixões, segundo Hume}

Para Meyer (2000), o gênero epidítico, assim como os outros gêneros, tem uma função específica. Se a função do gênero deliberativo é deliberar o que é útil, com base em decisões ou conselhos com perspectivas futuras; no gênero

7 Hume, $1958 \mathrm{~b}$ 
judiciário é pleitear o justo, visando à defesa, ao ataque ou à demanda com relação a certa questão passada; no caso do epidítico, a função é enfatizar, por meio de elogios ou censuras, o que é belo ou feio, justo ou injusto, ético ou antiético, ou qualquer outro "valor", como também pode ser apropriado a cerimônias solenes com a finalidade de elogios ou censuras, servindo-se sempre do verbo no presente.

Reboul revela que o discurso "epidíctico censura e, na maioria das vezes, louva um homem ou uma categoria de homens, como os mortos na guerra, ora uma cidade, ora seres lendários, como Helena". ${ }^{8}$ Tem-se, portanto, exemplos de discursos epidíticos louvando e censurando, sendo essa a sua função. Nesta pesquisa sobre o filósofo David Hume e as paixões, observa-se os estudos do filósofo voltados à razão movida pela paixão, que leva as pessoas a juízos em relação ao outro. O filósofo trata das paixões diretas como sensações de desejo e aversão; e as indiretas são o orgulho e a humildade. Desse modo, dessas paixões estudadas por Hume, ressalta-se o discurso epidítico, que é levado por essas paixões contraditórias, e que podem nos conduzir a louvar atitudes de um ser, ou desprezá-lo, dependentemente das nossas paixões e, conforme o autor, independentemente das nossas razões.

Assim, confirma o autor: "Em suma, uma paixão tem de ser acompanhada de algum juízo falso para ser contrária à razão; e mesmo então, não é propriamente a paixão que é contrária a razão, mas o juízo".

No caso do epidítico, cuja característica principal é ressaltar qualidades ou defeitos, pode-se não ter o objetivo de provocar debates, mas, mesmo indiretamente, sempre provoca reflexões, reconceitos, reavaliações. O discurso epidítico é um auxiliar na "arte de persuadir": "Cremos que os discursos epidíticos constituem a parte central da arte de persuadir e a incompreensão manifestada em relação a ele resulta da falsa concepção dos efeitos da argumentação". ${ }^{10}$

Verificando esse conceito de Perelman e Olbrechts-Tyteca sobre o discurso epidítico, Reboul, da mesma forma, exemplifica didaticamente as características dos três tipos de discursos:

8 Reboul, 2000, p. 45

9 Hume, 2009, p. 452

10 Perelman; Olbrechts-Tyteca, 1996, p. 64 
As paixões no discurso jornalístico: um estudo dos conceitos

de David Hume em confluência com os estudos retóricos

Quadro 1 - Os três gêneros do discurso

\begin{tabular}{|l|l|l|l|l|l|}
\hline & Auditório & Tempo & Ato & Valores & Argumento-tipo \\
\hline Judiciário & Juízes & Passado & Acusar & Justo & $\begin{array}{l}\text { Entimema } \\
\text { (dedutivo) }\end{array}$ \\
\hline Deliberativo & Assembleia & Futuro & $\begin{array}{l}\text { Aconselhar } \\
\text { Desaconselhar }\end{array}$ & $\begin{array}{l}\text { Útil } \\
\text { Nocivo }\end{array}$ & $\begin{array}{l}\text { Exemplo } \\
\text { (indutivo) }\end{array}$ \\
\hline Epidíctico & Espectador & Presente & $\begin{array}{l}\text { Louvar } \\
\text { Censurar }\end{array}$ & $\begin{array}{l}\text { Nobre } \\
\text { Vil }\end{array}$ & Amplificação \\
\hline
\end{tabular}

Fonte: Reboul (2000, p. 47)

Assim, entende-se, de forma mais precisa, do que tratam os gêneros epidíticos. Aqui será tratado o gênero epidítico no ato louvável.

Reboul pontua as definições de Aristóteles sobre os gêneros e o pathos:

Aristóteles define três tipos de argumentos, no sentido generalíssimo de instrumentos de persuadir: ethos, pathos, logos (...) O pathos é o conjunto de emoções, paixões e sentimentos que o orador deve suscitar no auditório com seu discurso. ${ }^{11}$

Já de acordo Ferreira: "para desvendar os sentidos de um texto, recomenda-se interrogar o próprio texto exaustivamente, a fim de encontrar os lugares da interpretação". ${ }^{12}$ Desse modo, entende-se que o discurso epidítico tem uma função retórica que consiste em estabelecer laços comunitários através da amplificação de valores comuns em função dos quais se poderá argumentar.

Diante dessas afirmações, pode-se partir para as análises. 


\section{Análise do corpus}

Para alinhar os conceitos de Hume ao gênero epidítico que circula no cotidiano, trazemos como exemplo um texto publicado na revista Veja no ano de 2016 que louva a então vice-primeira-dama, Marcela Temer. O título da matéria era: "Bela, recatada e do lar". E assim discorre num discurso ressaltando qualidades de Marcela Temer:

Marcela Temer é uma mulher de sorte. Michel Temer, seu marido há treze anos, continua a lhe dar provas de que a paixão não arrefeceu com o tempo nem com a convulsão política que vive o país - e em cujo epicentro ele mesmo se encontra. Há cerca de oito meses, por exemplo, o vice-presidente, de 75 anos, levou Marcela, de 32, para jantar na sala especial do sofisticado, caro e badalado restaurante Antiquarius, em São Paulo. Blindada nas paredes, no teto e no chão para ser à prova de som e garantir os segredos dos muitos políticos que costumam reunir-se no local, a sala tem capacidade para acomodar trinta pessoas, mas foi esvaziada para receber apenas "Mar" e "Mi", como são chamados em família. Lá, protegido por quatro seguranças (um na cozinha, um no toalete, um na entrada da sala e outro no salão principal do restaurante), o casal desfrutou algumas horas de jantar romântico sob um céu estrelado, graças ao teto retrátil do ambiente. Marcela se casou com Temer quando tinha 20 anos. O vice, então com 62, estava no quinto mandato como deputado federal e foi seu primeiro namorado. [...] $\mathrm{Na}$ opinião do cabeleireiro, Marcela "tem tudo para se tornar a nossa Grace Kelly". Para isso, falta só "deixar o cabelo preso". Em todos esses anos de atuação política do marido, ela apareceu em público pouquíssimas vezes. "Marcela sempre chamou atenção pela beleza, mas sempre foi recatada", diz sua irmã mais nova, Fernanda Tedeschi. [...] Michel é um homem de sorte. ${ }^{13}$ 
As paixões no discurso jornalístico: um estudo dos conceitos

de David Hume em confluência com os estudos retóricos

Figura 1 - Matéria da revista Veja

\section{"Bela, recatada e do lar" é forma infeliz de descrever alguém}

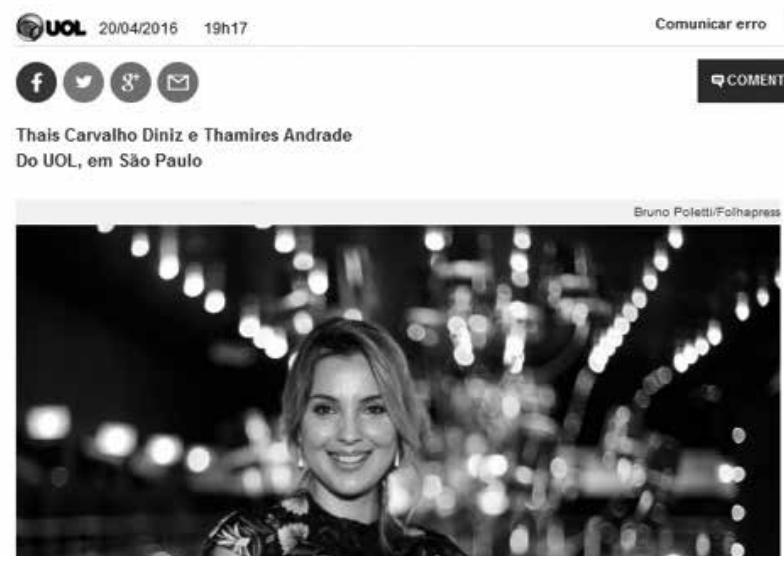

Fonte: Linhares (2016)

O discurso publicado pela revista Veja, apesar de laudatório causou grande impacto na sociedade. Seguindo a concepção de Perelman e Olbrechts-Tyteca (1996), o discurso epidítico tem o interesse de persuadir, porém pode causar incompreensão manifestada pela população, destruindo-se os seus efeitos de argumentação.

Na concepção de Hume (1958a, 1958b), esse mecanismo de simpatia que possibilita aproximar sentimentos nas relações pessoais se torna fundamental para expandir a compreensão das paixões. Ou seja, em relação ao conceito humeano, podemos observar que a revista, na tentativa de provocar simpatia, valeu-se da humildade ou até mesmo da linearidade da vice-primeira-dama com as milhares de mulheres brasileiras donas de casa. Na contração dessa tentativa, o efeito foi de antipatia, desprezo pelo discurso da revista.

Assim, é possível ver nas manchetes posteriores à matéria:

O texto gerou polêmica e, na quarta-feira (20), milhares de pessoas, anônimas e famosas, publicaram em suas redes sociais "memes" ironizando as características atribuídas pela publicação à vice -primeira-dama, consideradas misóginas e atrasadas. A hashtag composta das palavras "bela, recatada e 'do lar"' foi uma das mais citadas do dia no Twitter. ${ }^{14}$ 
A revista empenhou-se em criar uma imagem para a Marcela, numa tentativa de pertencimento ao contexto do auditório. Mas, considerando as experiências e a maneira como o ser humano se vê em relação ao seu semelhante e se identifica, o auditório (feminino) não se identificou com a realidade da vice-primeira-dama e reconheceu no discurso um peso machista em relação às palavras que soaram no título "Bela, recatada e do lar", bastante semelhante ao das matérias das revistas dos anos de 1950 e 1960, em que o machismo imperava e a mulher carregava a obrigação de ser bela e obediente ao esposo. Cunha (2001) afirma que, entre as décadas de 1960 e 1970, os concursos de beleza feminina eram vistos com grande importância e a mulher era definida por alguns como a expressão maior da identidade mulher/objeto, mulher/produto, ou seja, destaca a atenção que essas competições obtinham por parte da imprensa, com direito a reportagens que se avolumavam em quantidade de páginas considerável.

"Nenhuma paixão alheia se revela imediatamente à nossa mente. Somos sensíveis apenas às suas causas ou efeitos. É desses que inferimos a paixão, consequentemente, são eles que geram nossa simpatia. ${ }^{15}$ Essa afirmação de Hume explica o sentimento de cada brasileira e leitora do discurso da revista. As mulheres que se sentiram ofendidas pelo discurso não poderiam "ler" a paixão que se revelava na autora do texto, mas sentiram seus efeitos, e assim inferiram a paixão, sendo essa paixão nomeada pelo filósofo como direta, pelo tom machista, gerando a antipatia, a aversão pelo discurso laudatório dirigido à Marcela Temer.

Como já foi dito, Hume divide as paixões em diretas e indiretas. A diferença entre os dois tipos de paixão deve-se, essencialmente, ao seu grau de "imediatismo." As paixões diretas provêm do bem e do mal, do prazer e da dor; originam-se do contato imediato do corpo com os objetos exteriores e devem muito da sua existência às estruturas originais do nosso corpo. Aqui, na definição das paixões diretas, poderíamos observar uma ideia utilizada pelo filósofo e que serviria como um importante "traço" para a definição da sua teoria das paixões. As paixões diretas se constituiriam, basicamente, em sete: desejo e aversão, tristeza e alegria, esperança e medo e volição.

Como já observado, David Hume tem uma postura ponderada no que diz respeito ao uso da razão, denotando a importância na deliberação e na orientação do impulso da paixão. Linhares, no entanto, autora da matéria em comento, colocou no seu texto elementos que intencionalmente despertariam paixões como amor, humildade, alegria, porém o que ocorreu foi na contramão da intenção do texto: o auditório respondeu com aversão, repulsa, ódio ao discurso laudatório

15 Hume, 2009, p. 615, grifo do autor 
As paixões no discurso jornalístico: um estudo dos conceitos

da jornalista. Percebe-se, porém, que o auditório do gênero epidítico teve um papel não só de espectador, mas logo assumiu a função de juiz, acusando com base no valor de justiça.

\section{$\mathrm{O}$ ato retórico}

O ato retórico se constrói, então, por uma ação da jornalista, que atua sobre o entendimento do auditório, e a vontade da autora: o argumento em favor de Marcela Temer.

Vale ressaltar o gênero discursivo empregado é o epidítico, ou seja, louva-se o casal Michel Temer, então vice-presidente da República, e Marcela Temer, vice -primeira-dama, porém com enfoque na ex-primeira-dama. O assunto tematizado é de natureza política, pois tenta apresentar, ou fantasiar, os personagens Michel e Marcela, trazendo preocupação com a coletividade, partilhando a vivência do casal "comum" e pondo em relevo uma vice-primeira-dama que leva também uma vida "comum". O texto também apresenta traços do gênero deliberativo, que faz do auditório assembleia. É interessante observar que, no contexto em que se insere, o fato requer que o leitor apenas manifeste concordância ou discordância a respeito do que foi dito pela jornalista, que tenta exercer profunda influência no auditório, e simultaneamente louvar as qualidades de Marcela Temer. Explora despudoramente as características do gênero epidítico, que é dominante no texto, a começar pelo título. De acordo Ferreira (2015), o gênero epidítico compreende tanto um discurso que louva, exalta, glorifica, como também o que censura, afronta, menospreza, e isso permite ao autor explorar assuntos que se associam a valores ligados ao belo e ao feio, que enaltecem a virtude, que desaprovam o vício, os desmandos e os maus hábitos, ou seja, o discurso epidítico pode ao mesmo tempo reprimir ou elogiar.

As provas retóricas possuem objetivo claro: persuadir. Sustentam-se sobre raciocínios que se constituem no que se conhece por argumentos. Por exemplo, neste trecho:

Marcela se casou com Temer quando tinha 20 anos. O vice, então com 62, estava no quinto mandato como deputado federal e foi seu primeiro namorado.(...)

Na opinião do cabeleireiro, Marcela "tem tudo para se tornar a nossa Grace Kelly". Para isso, falta só "deixar o cabelo preso". Em todos esses anos de atuação política do marido, ela apareceu em público pouquís- 
simas vezes. "Marcela sempre chamou atenção pela beleza, mas sempre foi recatada", diz sua irmã mais nova, Fernanda Tedeschi. ${ }^{16}$

Aqui, a jornalista ressalta provas extrínsecas, por meio de depoimentos de outras pessoas (cabeleireiro e a irmã). Em relação aos lugares, a oradora valeuse de muitas formas de criar argumentos que movessem seu auditório. Ferreira aborda a definição de Aristóteles a respeito de lugares retóricos: "o pensador grego, havia o lugar do acidente, da definição, da divisão, da etimologia, do gênero, da espécie, diferença, propriedade, casualidade, termos contrários e vários outros" ${ }^{17} \mathrm{O}$ autor define que os lugares, ligam-se à exploração da hierarquia de valores do auditório, pretendem reforçar a intensidade da adesão que suscitam e ficam à disposição do orador para criação dos argumentos.

Nesse âmbito, entende-se como a oradora utilizou os argumentos/lugares para enfatizar sua argumentação: lugares da qualidade; derivado do valor de pessoa; da beleza; do status, da tradição; do luxo.

Quadro 2 - Argumentos/lugares

"Bela, recatada e do lar"

Marcela "tem tudo para se tornar a nossa Grace Kelly".

Marcela sempre chamou atenção pela beleza, mas sempre foi recatada

(...) o vice-presidente, de 75 anos, levou Marcela, de 32, para jantar na sala especial do sofisticado, caro e badalado restaurante Antiquarius, em São Paulo. Blindada nas paredes, no teto e no chão para ser à prova de som e garantir os segredos dos muitos políticos...

Fonte: Linhares (2016, [s.p.])

Esses lugares utilizados pela oradora são muito empregados na publicidade. Dessa maneira, o texto jornalístico abordado neste capítulo se aproxima de uma propaganda, uma tentativa de rotulagem de um produto à venda - nesse caso, o produto em destaque seria Marcela Temer. Porém, a tentativa tornouse frustrante, pois o auditório específico, que deveria ser apenas espectador, converteu-se em juiz e entendeu que os elementos passionais empregados - o gênero epidítico, as provas extrínsecas, os lugares retóricos - serviram como 
As paixões no discurso jornalístico: um estudo dos conceitos

uma afronta à população, em especial às mulheres. Os termos "Bela, recatada e do lar" soaram machistas e arcaicos: a obrigação de ser recatada e ainda ser uma submissa dona de casa, num momento em que as mulheres se obstinam a mudar os estereótipos arraigados em nossa cultura.

\section{Considerações finais}

A primeira consideração acerca do estudo desenvolvido neste capítulo diz respeito ao fato de conseguir promover um diálogo entre um filósofo (e seus conceitos em relação às paixões) e os estudo retóricos. Isso foi possível em razão da interdisciplinaridade, a qual ensina que as manifestações linguísticas necessitam de perspectivas diferentes para serem compreendidas em sua integralidade. Neste capítulo, procurou-se unir o conceito de David Hume acerca da classificação das paixões aos estudos retóricos que envolvem o pathos, com todos os elementos passionais utilizados pelo orador, intencionalmente, para mover seu auditório.

Por fim, é importante ressaltar o papel da retórica no texto "Bela, recatada e do lar". É imprescindível o trabalho retórico da oradora. Com base nas teorias utilizadas para análise, verifica-se a influência sobre o auditório, a investida da oradora nas provas extrínsecas (o cabeleireiro e a irmã Fernanda), para reforçar sua tese de "Bela, recatada e do lar", e a prova intrínseca, para relatar Marcela como uma boa esposa, como se a conhecesse na intimidade do lar. O excesso de lugares (qualidade, beleza, derivado do valor de pessoa, status, tradição e do luxo), para apoiar as provas empregadas pela oradora. Então, nessas estratégias de persuasão, entra o auditório: considerando o gênero epidítico, deveria ser espectador, porém toma o lugar de juiz e, assim, adentra o entendimento de Hume, no esquema que foi apresentado no início deste capítulo:

\section{RAZÃO $\rightarrow$ MORAL PAIXÕES $\rightarrow$ RAZÃO $\rightarrow$ MORAL}

Compreendendo a classificação do filósofo, na temática do texto apresentado, pode-se considerar, valendo-se dessa confluência dos dois estudos aqui abordados, que a resposta do auditório particular desse texto (as mulheres) foi totalmente envolvida pelas paixões diretas e indiretas explicadas por Hume, nesse contexto observa-se o envolvimento de: orgulho (proferido no discurso à vice-primeira-dama), aversão (auditório obteve aversão ao discurso) e ódio (o misto das paixões diretas ocasionou na paixão indireta). 
E esse auditório agiu por ter sua moral ferida, principalmente, pela frase que intitulou o texto ("Bela, recatada e do lar"). E assim foi tomado pela razão de considerar os termos machistas, que priorizam o estereótipo de mulher bonita e "escrava do lar", num mundo de transformações, em que a mulher busca seu espaço destruindo o pensamento arraigado no machismo, no estereótipo de beleza - no qual a mulher tem de ser magra e com características europeias (loira), não ter direitos trabalhistas iguais aos do homem, tendo de ser "do lar" e viver na submissão masculina. Dos dados colhidos na análise do corpus e pelo material teórico aqui estudado, foi possível aludir esta conclusão.

\section{Referências}

CUNHA. M. F. Homens e mulheres nos anos 1960/1970: um modelo definido? História: Questões \& Debates, Curitiba, Editora da UFPR, n. 34, p. 201-222, 2001. Disponível em: https://revistas.ufpr.br/historia/article/viewFile/2665/2202. Acesso em: 13 ago. 2020.

DINIZ, T. C.; ANDRADE, T. "Bela, recatada e do lar" é forma infeliz de descrever alguém. BOL Notícias, São Paulo, 24 abr. 2016. Disponível em: https://noticias.bol.uol.com.br/ ultimas-noticias/entretenimento/2016/04/20/bela-recatada-e-do-lar-e-forma-infelizde-descrever-alguem.htm. Acesso em: 6 ago. 2020.

FERREIRA, L. A. Leitura e persuasão: princípios de análise retórica. São Paulo: Contexto, 2015 .

HUME, D. A treatise of human nature. Oxford: Carendon Press, 1958a.

. Tratado da natureza humana. São Paulo: Unesp, 1958b.

Tratado da natureza humana: uma tentativa de introduzir o método experimental

de raciocínio nos assuntos morais. Trad. Debora Danowski. 2. ed. rev. e ampliada. São Paulo: Editora UNESP, 2009.

Dissertação sobre as paixões. Natal: Princípios, 2011.

LINHARES, J. Marcela Temer: bela, recatada e "do lar". Veja, [s. l.], 18 abr. 2016. Disponível em: https://veja.abril.com.br/brasil/marcela-temer-bela-recatada-e-do-lar/. Acesso em: 10 abr. 2020.

MACARENHAS, R. S. A teoria das paixões na filosofia de David Hume. 2005. Dissertação (Mestrado em Filosofia) - UFBA, Salvador- BA, 2005. Disponível em: https://repositorio. ufba.br/ri/handle/ri/9573. Acesso em: 6 ago. 2020.

MEYER, M. Aristóteles ou a retórica das paixões. In: ARISTÓTELES. Retórica das paixões. Trad. Isis Borges da Fonseca. São Paulo: Martins Fontes, 2000. p. XVII-LI

PERELMAN, C.; OLBRECHTS-TYTECA, L. Tratado da argumentação: a nova retórica. Prefácio de Fábio Ulhôa Coelho; tradução de Maria Ermantina Galvão G. Pereira. São Paulo: Martins Fontes, 1996.

REBOUL, O. Introdução à retórica. São Paulo: Martins Fontes, 2000. 